\title{
|فتناحية العدد
}

عزيزي القارئ.. يسعد كلية الآداب - جامعة القاهرة أن يَرج عدد جديد

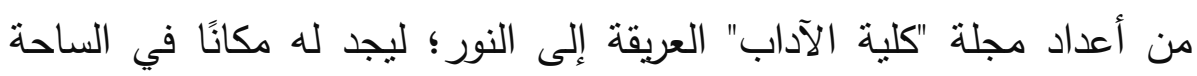

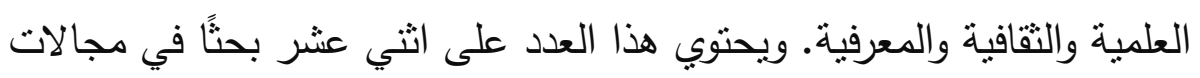

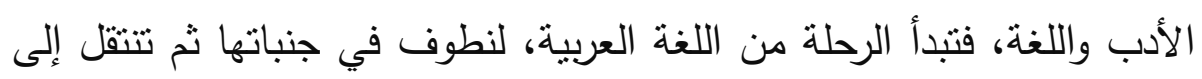

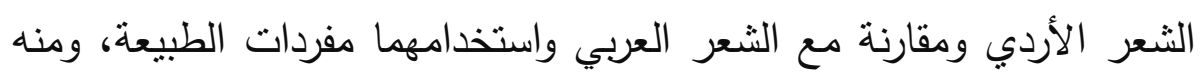

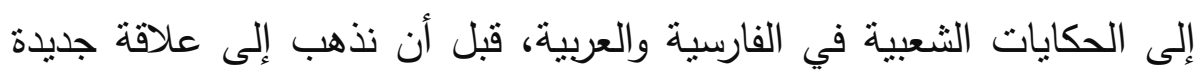

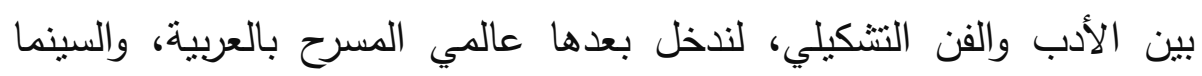
بالفرنسية، ثم نذهب إلى نصف العالم الآخر حيث اللغة الصينية لننهي الرحلة هناك.

وتُعلن بداية الرحلة من القرآن الكريم؛ حيث يحمل البحث الأول عنوان:

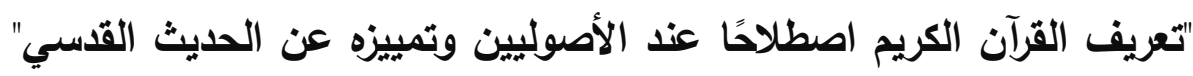

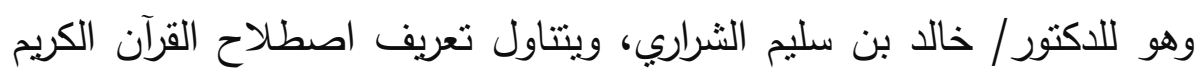

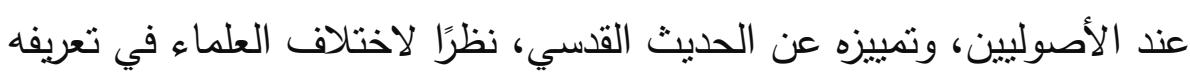

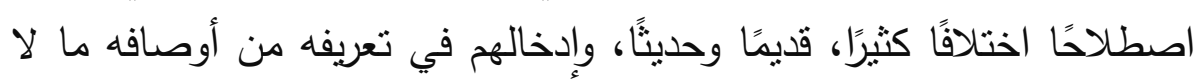

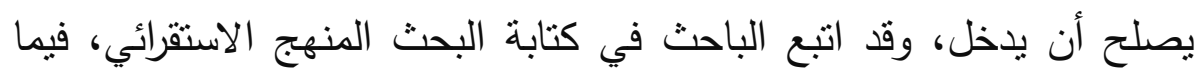
يتعلق بالرجوع إلى مصادر البحث.

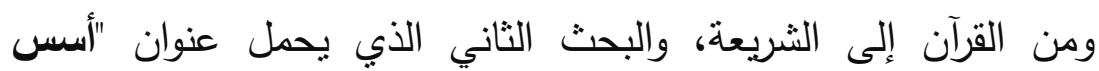

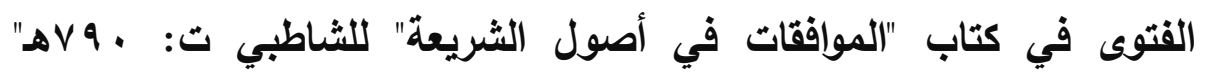

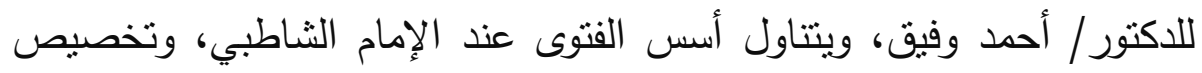

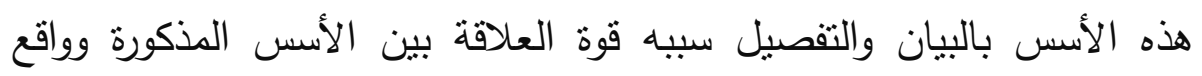

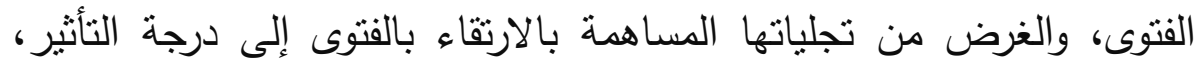

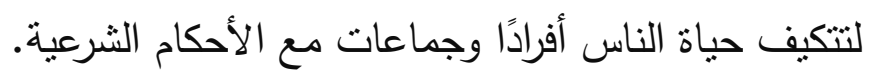

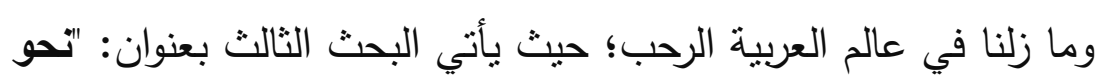




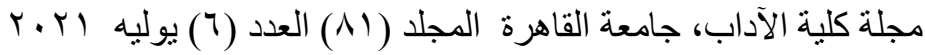

تحليل النص اللغوي - قراءة في الكتاب "لسيبويه"، للدكتور/ محمد إبراهيم

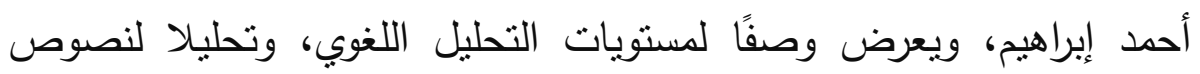
سييويه بهدف استخلاص العناصر التي يمكن من خلالها تحليل أي نص لغوي اعتمادًا على ما قدمه سيبويه. لئه

ومنه إلى البحث الرابع المعنون ب"قضايا المفكوك في اللغة العربية: جمع ودراسة لغوية"، للاكتور/ شيرين ياسين، ويهدف البحث إلى دراسة القضايا الصوتية، والصرفية، والنحوية المتعلقة بالأسماء والأفعال المفكوكة في لإنينة اللغة العربية.

وما بين الشعر العربي والثعر الأردي نقف مع بحثنا الخامس "مفردات الطبيعة في الشعر الأردي والعربي: "مجيد أمجد" و"محمود شعبان" نموذجَا، دراسة مقارنة" للاكتورة/ تغريد محمد البيومي السيد، ويعرض البحث مفردات الطبيعة الصامتة، ومفردات الطبيعة الحية عند الثاعرين، كما يتطرق إلى أوجه الثبه والاختلاف بينهما.

ولا يفوتتا في الرحلة أن نذهب إلى الحكايات الثعبية من خلال بحثنا السادس و "مكانة الوزير لاى الرغبة في الحكايات الشعبية الفارسية والعربية (دراسة مقارنة)" للاكتور / هاشم محمد هاشم، ويعرض لنا الباحث دراسة مقارنة بين مكانة الوزير لدى الرعية في إيران ومصر من خلال عرض مجموعة من هن ماته الحكايات الثعبية التي جمعت من مناطق منتوعة وأعراق مختلفة في إيران ومصر، حيث يؤدي ذلك إلى إبراز الرؤى المتعددة لمكانة الوزير في المناطق المختلفة داخل إيران ومصر •

وننطلق بعدها إلى بحثنا السابع: "تقد النصوص المترجمة العربية من اليونانية ونشرها: القواعد والإشكاليات" للاكتورة/ نشوى جمعة ضيف الله، ويقدم العديد من الإشكاليات التي تعترض المحقق أثناء ترجمته الكتب من 
اليونانية إلى العربية، سواء التي تختص بجمع النسخ وفحصها وترتيبها، أو ما يتعلق بالمحتوى العلمي للنص من صعوبات، من خلال المناقثة لأهم المصطلحات المستخدمة في تحقيق النصوص، مع ذكر المقابل اللتيني لها كلما أمكن ذلك.

وما بين القديم والمعاصر ، والثعر والفن التشكيلي تأتي المحطة التالية في رحلتتا؛ حيث البحث الثامن الذي يحمل عنوان "العلامة اللغوية والعلامة البصرية ودورهما في تشكيل صورة الحرب (معلقة زهير بن أبي سلمى وجدارية جرتيكا لبابلو بيكاسو نموذجا" للاكتورة/ عزة شبل محمد أبو العلا، وتسعى الدراسة إلى التعرف على دور العلامات سواء اللغوية، أو المرئية في تشكيل صورة الحرب، ومحاولة الكثف عن أنماط الصورة، ووظائفها التواصلية من خلال معلقة زهير بن أبي سلمى، وجدارية (جرتيكا) لبابلو بيكاسو، حيث اشترك كلاهما في توجيه خطاب إنساني عام بطالب بنبذ الحروب، والدعوة إلى لى لئ السلام.

وننطلق في رحلتنا إلى فضاء المسرح الرحب لنجد بحثنا التاسع

"ديالكتيكية الموروث والوافد في المسرح الاستعراضي المصري - دراسة في مسرح علي الكسار"، للاكتور/ تامر فايز ، وتبحث هذه الدراسة في قضية نشأة المسرح الاستعراضي، وقد بُنيت على تأثرنا بالتيارين الفكريين؛ تيار الأصالة وتيار المعاصرة، بوصفهما نيارين مؤثرين على الإبداع العربي بمختلف تشكيلاته، وقد أنتج هذا ما سمي في هذه الدراسة بديالكتيكية الوافد والموروث في المسرح الاستعراضي المصري، وخاصة مسرح علي الكسار • وإذا كان للمسرح العربي نصيب في رحلتنا، فإن الرحلة تمتد لنذهب إلى السينما لنلتي مع بحثنا العاشر باللغة الفرنسية، وعنوانه "التناول المسرحي وغير الثقافي في السينما لكوميديا موليير"، للاكتورة/ هايدي سامي زكي، وتعرض الباحثة قراءة سميوطيقية لفيلم "قصة ممنوعة" المقتبس من المسرحية 


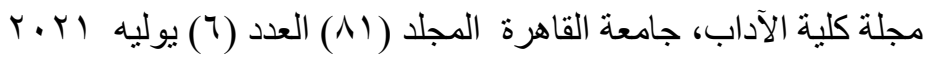
Ir

الكوميدية "مدرسة النساء" لموليير ، وهي قراءة متعمقة باستخدام منظور غير ثقافي، ومقارن للتفكير في قضايا مثل عملية إعادة التناول التي تساعد في اكتشاف مساحات التقاطع بين العمل الدرامي والمنتج السينمائي. ومن الفرنسية نرحل إلى شرق آسيا حيث اللغة الصينية وبحثنا الحادي عشر بعنوان "المختصرات في اللغة الصينية وإثكاليات ترجمتها إلى العربية في العصر الحديث"، للباحث/ عادل حسين عبد السام، ويتتاول تعريف علم الترجمة وخصائصه، كونه تخصصًا لغويًا ذا طابع فني خاص، ويلقي البحث

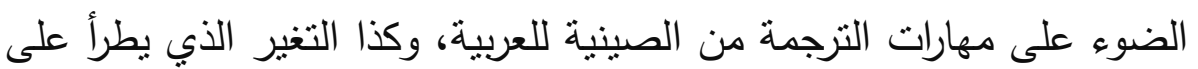
النص العربي نظرًا للاختلافات الموجودة بين اللغتين في العديد من الظواهر اللغوبة.

وباللغة الصينية أيضًا ننهي رحلتتا مع بحثنا الثاني عشر الذي يحمل التهل

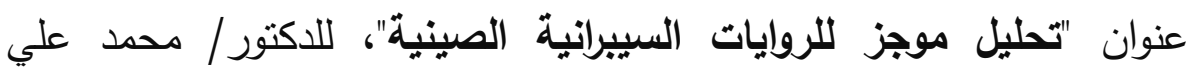
إبراهيم السيد، وتقدم الدراسة تحليلا للروايات السيبرانية الصينية، حيث خضعت هوجت هذه الروايات لتغييرات كبيرة في البنية السردية، والسياق السردي، ووسائل الإعلام السردي، نتيجة لدمج الإنترنت في حياتتا لتغير الطرق التي تدرس،

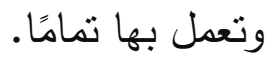

ونرجو أن يفيد الباحثون من هذه الرحلة التي طاف بنا فيها عدد من الباحثين المتميزين الذين نشكرهم على أبحاثهم الجادة التي لا تقل تميزًا. وعلى هلى لته وعد ولقاء جديد وأعداد جديدة من مجلتكم مجلة "كلية الآداب". وعلى الله قصد السبيل..

رئيس التحرير

أ.د. عبيز محمد عبد السلام

وكيل كلية الآداب لشئون الدراسات العليا والبحوث 